\title{
PROTOTYPE APLIKASI PENGINAPAN HAWAKAS CILILITAN BERBASIS JAVA
}

\author{
Harun Suswanto ${ }^{1,}$ Dian Novita ${ }^{2}$ \\ Program Studi Infomatika, Fakultas Teknik dan Ilmu Komputer, Universitas Indraprasta PGRI ${ }^{1,2}$ \\ suswantoharun@gmail.com, Dyan.novita21@gmail.com
}

\begin{abstract}
Abstrak
Tujuan Penelitian adalah untuk membuat model rancangan aplikasi penyewaan penginapan yang efisien dan dapat membantu kinerja bagian pengurus pada saat pelayanan penghuni dan proses penyewaan. Metode penelitian yang digunakan adalah metode field research yaitu metode penelitian untuk mendapatkan data dan informasi untuk mendukung penyempurnaan hasil dari penelitian ini. Peneliti menarik kesimpulan bahwa aplikasi ini dapat mempemudah bagian pengurus dalam proses penyewaan kamar dan proses transaksi. Pelayanan penghuni menjadi lebih efektif dan efisien karena terintegrasi dengan baik ke dalam database.
\end{abstract}

Kata Kunci: Penyewaan, Aplikasi, Penginapan, Java.

\begin{abstract}
The aim of the research is to create an efficient model of lodging rental applications that can help the performance of the board at the time of resident service and leasing process. The research method used is the field research method of research methods for obtaining data and information to support the improvement of the results of this research. Researchers have concluded that this application can be a part of the admin section in the room rental process and transaction process. The resident service becomes more effective and efficient as it integrates well into the database.
\end{abstract}

Keywords: Rentals, Applications, Accommodation, Java

\section{PENDAHULUAN}

Perancangan sistem adalah penetuan proses dan data yang di perlukan oleh sistem baru, jika itu berbasis komputer, perancangan dapat dinyatakan spesifikasi peralatan yang digunakan. Hal ini dimungkinkan karena teknologi komputer mampu berkolaborasi dengan banyak bidang ilmu lainnya. Implementasi teknologi informasi berperan untuk mendukung kegiatan operasional suatu organisasi baik dalam menghadapi era globalisasi. Berbagai macam perangkat teknologi informasi untuk infrastruktur, service, maupun aplikasi, saat ini banyak tersedia di pasaran dalam berbagai bentuk dan fungsi. Hal ini menyebabkan banyaknya alternatif solusi teknologi informasi yang perlu dipertimbangkan, dalam menentukan kebijakan pengembangan organisasi. Implementasi teknologi informasi dalam kegiatan operasional organisasi akan memberikan dampak yang cukup signifikan, bukan hanya dari segi efisiensi kerja, tetapi juga terhadap budaya kerja baik secara personal, antar unit, maupun keseluruhan institusi.

Adapun sistem berjalan di Penginapan Hawakas masih secara manual dimana para penghuni datang langsung ke penginapan untuk menanyakan kamar yang kosong yang akan memakan waktu, dimana para penghuni datang untuk melihat kamar yang kosong. Oleh karena itu, peneliti membuat sistem usulan berupa pemesanan kamar secara komputerisasi berbasis java. Dengan adanya sistem pemesanan kamar ini maka pelanggan akan lebih mudah membooking kamar.

Maka judul penelitian ini berdasarkan permasalahan di atas yakni Prototype Aplikasi Penginapan Hawakas Cililitan Berbasis Java.

Berdasarkan masalah tersebut maka ada beberapa solusi yang ditawarkan adalah masalah yang lebih spesifik agar dapat dimanfaatkan oleh pengurus penginapan dengan baik. Pembatasan aplikasi penginapan yang akan dibuat sebagai berikut:

a. Mencatat / menyimpan data-data yang berkaitan dengan customer ke dalam bentuk digital.

b. Membuat aplikasi penginapan hawakas yang sesuai dengan kebutuhan penginapan.

c. Merancang sebuah sistem yang mampu meminimalkan resiko kesalahan dalam membuat perjajian booking. 


\section{PENELITIAN RELEVAN}

Kustian (2019) menjelaskan bahwa pengujian menggunakan sekumpulan aktivitas validasi dengan pendekatan black box testing sedangkan Black box testing merupakan alat untuk menguji perangkat lunak dari segi spesifikasi fungsional tanpa menguji desain dan kode program. Sedangkan Maria Agustin (2012) dari hasil penelitiannya melakukan penelitian terhadap hotel yang bertujuan mempermudah proses pemesanan kamar oleh pelanggan hotel. Proses pertama kali yang datang adalah pelanggan mendatangi hotel untuk melakukan check in, namun sebelum pelanggan melakukan check in pelanggan dapat menghubungi pihak hotel. Dari hasil penelitian Mayasari (2015) terhadap tempat penyewaan kaset (CD) adalah data yang diolah menjadi bentuk yang lebih berarti bagi penerimanya dan bermanfaat dalam mengambil keputusan. Istilah informasi mengarah pada penggunaan teknologi komputer didalam organisasi untuk menyajikan informasi kepada pemakai”. Dengan adanya aplikasi penyewaan futsal berbasis web, maka pihak penyewa dapat melihat data - data customer yang memesan lapangan secara otomatis dan juga melihat semua data - data pemesanan dari keseluruhan jumlah penyewa perhari sampai keseluruhan pendapatan yang diperoleh (Maimunah; Hariyansyah; Jihadi, 2017). Dengan adanya aplikasi pencarian kost ini pencarian informasi kost menjadi lebih mudah dan efisien serta mendetail tanpa harus datang langsung ke lokasi (Rosadi \& Feby, 2016).

\section{METODE PENELITIAN}

Metode pengumpulan data yang dilakukan oleh peneliti untuk mendapatkan data-data dan informasi untuk mendukung penyempurnaan hasil dari penelitian ini, antara lain:

\section{Studi Lapangan (Field Research)}

\section{1) Observasi}

Observasi merupakan suatu cara pengumpulan data dengan mengadakan pengamatan langsung terhadap suatu objek dalam suatu periode tertentu dan mengadakan pencatatan secara sistematis tentang hal-hal tertentu yang diamati. Peneliti mempelajari dan mengamati dengan teliti sistem pendataan data penghuni yang ingin membooking kamar di penginapan hawakas.

\section{2) Wawancara}

Wawancara merupakan suatu teknik pengumpulan data yang dilakukan dengan cara tanya jawab antara penanya (interviewer) dengan penjawab (responden). Peneliti melakukan interview kepada pemilik penginapan hawakas. Pada wawancara kali ini secara umum peneliti menanyakan bagaimana sistem booking pada kamar calon penghuni yang berjalan di penginapan yang berjalan di penginapan hawakas tersebut.

3) Sumber Data

Data dan informasi yang diperoleh untuk menguatkan penelitian diambil dari berbagai sumber yaitu sumber data sekunder yang merupakan data pendukung untuk melengkapi data premier yang diperoleh melalui tanya jawab langsung atau dokumen.

\section{4) Studi Kepustakaan}

Studi kepustakaan bertujuan untuk memahami dan menguatkan dasar teori yang berhubungan dengan analisa kebutuhan yang telah dilakukan. Peneliti melakukan studi kepustakaan dari berbagai media seperti buku, jurnal, modul, artikel, dan lain sebagainya, yang berhubungan dengan analisis dan perancangan sistem.

\section{Perancangan Sistem}

\section{1) Merancang Database}

Perancangan database berfungsi untuk menyimpan data-data yang telah dimasukan Dan digunakan sebagai sumber informasi oleh pengguna.

2) Merancang Antarmuka

1. Hal terpenting yang harus di perhatikan dalam merancang tampilan antarmuka adalah si perancang harus memiliki jiwa seni yang kuat dalam mendesain tampilan antarmuka program.

2. Mengerti selera pengguna secara umum.

3. Melakukan dokumentasi rancangan, agar rancangan dapat diubah dengan cara:
(a) Membuat sketsa pada kertas
(b) Menggunakan piranti prototype 
(c) Menerangkan keterkaitan jendela satu dengan yang lainnya, dan menggunakan piranti bantu

\section{3) Mengembangkan Antarmuka}

Di dalam melakukan pengembangan antarmuka, hal yang harus diperhatikan adalah membangun prototype. Membangun prototype adalah cara yang berharga dalam membuat rancangan awal dan membuat demonstrasi, maka sangat penting untuk melakukan pengujian kegunaan antarmuka. Dari prototype tersebut, perancang antarmuka dapat mulai membangun tampilan secara utuh. Ketika membuat prototype, penting diingat bahwa prototype harus dapat dibuang setelah digunakan, di mana tujuan pembuatan prototype adalah untuk mempercepat desain alternative dan konsep, bukan untuk membangun kode program tersebut.

\section{4) Impelementasi Sistem}

Impelementasi atau pengkodean adalah proses menerjemahkan dokumen hasil desain menjadi baris-baris perintah bahasa pemogram komputer. Semakin baik hasil analisis dan desain yang dirancang, maka proses pengkodean akan lebih mudah dilakukan.

Proses impelementasi yang dilakukan peneliti terdiri atas langkah-langkah berikut:

1. Menerapkan rencana impelmentasi

rencana implementasi dimaksudkan untuk menghitung biaya dan waktu yang diperlukan selama masa pengimplementasian. Dalam rencana implementasian juga perlu diatur dalam bentuk jadwal tersusun. Anggaran biaya dan jadwal tersusun ini berfungsi sebagai pengendali terhadap biaya dan waktu yang dikeluarkan selama masa pengimplementasian.

2. Melakukan kegiatan implementasi

Kegiatan-kegiatan yang dilakukan selama masa pengimplementasian adalah sebagai berikut:

(a) Pengkodean dan evaluasi program

(b) Evaluasi sistem

(c) Konversi sistem

3. Tindak lanjut implementasi

Setelah sistem baru telah di implementasi, peneliti masih perlu melakukan tindak lanjut berikutnya. Peneliti bersama dengan admin, melakukan pengetesan program dengan menggunakan data sesungguhnya dalam jangka waktu tertentu.

4. Pengujian sistem

Pengujian adalah proses eksekusi program untuk menemukan kesalahan pada sistem serta untuk memastikan apakah semua fungsi sistem bekerja sesuai dengan kebutuhan admin. Pengujian sangat penting dilakukan untuk mendapatkan sistem yang benar-benar valid dan sesuai dengane kebutuhan menjamin kualitas program apakah sudah layak digunakan oleh admin atau belum.

\section{HASIL DAN PEMBAHASAN}

Aturan sistem yang diusulkan Penginapan Hawakas pada bagian pengolahan data Penginapan hawakas adalah sebagai berikut:

a. Ketika ada calon penghuni yang ingin membooking kamar, penghuni harus datang ke penginapan dan penghuni mengecek kamar yang kosong lalu penghuni mengisi form dengan data diri ketika sudah data diri.

b. pengurus menginput data diri penghuni untuk di masukan ke database data penghuni.

c. Setelah admin menginput data diri penghuni, penghuni melakukan pembayaran kepada pengurus kemudian pengurus memberikan kwitansi dan kunci kamar kepada penghuni.

d. Setelah itu pengurus mendata semua dan dijadikan laporan datapenghuni, pengeluaran, sewa kamar dan memberikan laporan tersebut ke pemilik penginapan

Berikut ini merupakan penggambaran tentang sistem yang diusulkan pada pengolahan data penginapan hawakas secara keseluruhan dalam bentuk diagram konteks. 


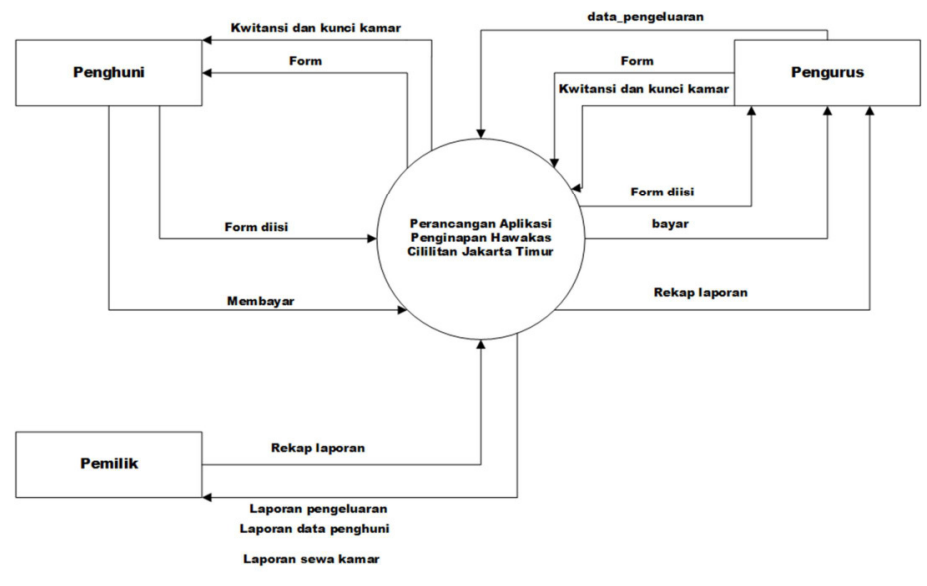

Gambar 1. Diagram Konteks Sistem Membooking Penginapan Hawakas

Selanjutnya peneliti membuat aplikasi dengan menggunakan Java berbasis desktop dan database mysql. Berikut ini adalah tampilan dari aplikasi penginapan pada penginapan hawakas :

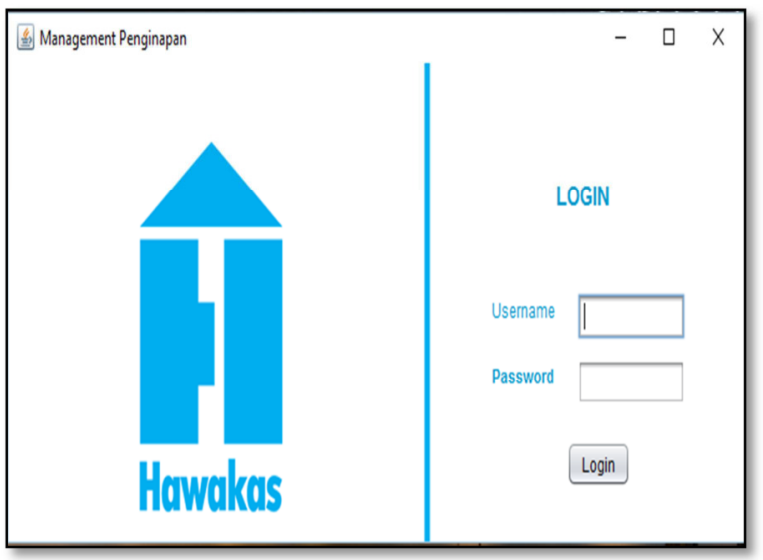

Gambar 2. Tampilan Menu Login

form ini digunakan sebagai kata kunci sebelum kita memasuki menu utama. Agar tidak sembarangan orang dapat mengakses aplikasi ini.

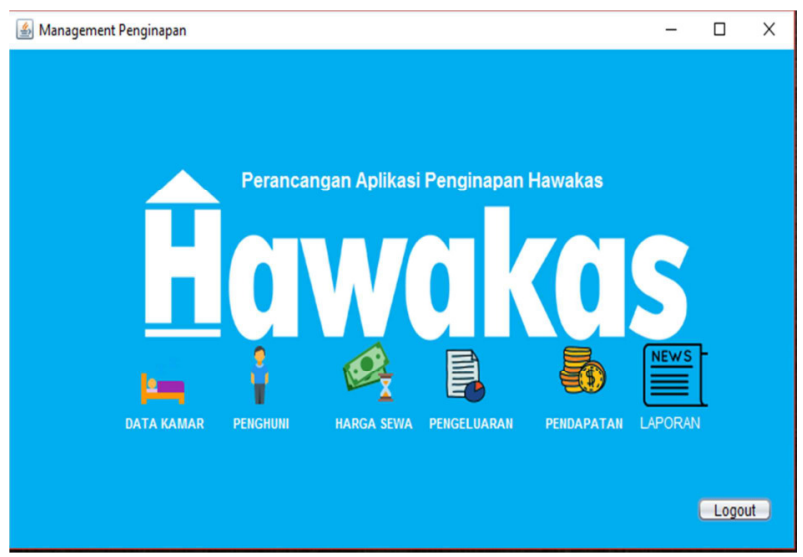

Gambar 3. Tampilan Menu Utama

Pada layar utama tersedia pilihan tombol button data kamar, penghuni, harga sewa, pendapatan pengeluaran, dan laporan. 


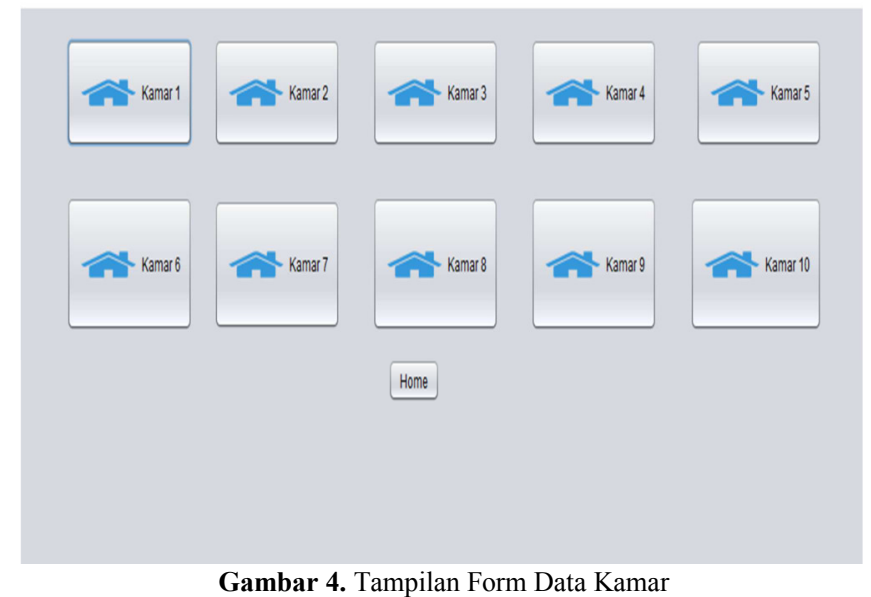

Pada form data kamar ini sebagai langkah awal terjadinya proses pembookingan kamar karna form ini untuk mengecek kamar kosong.

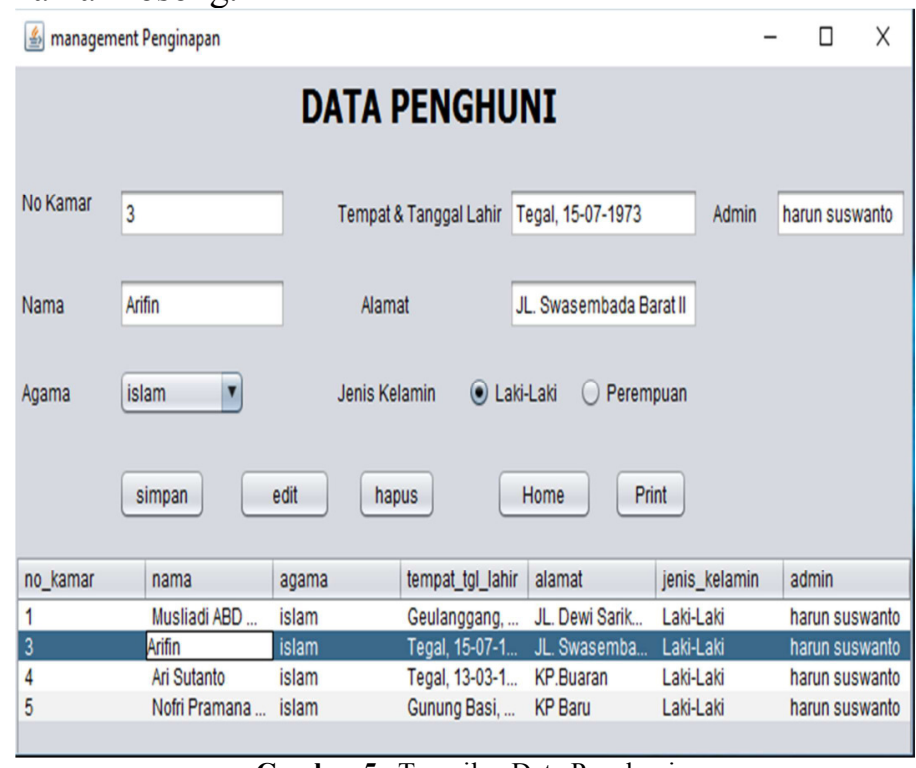

Gambar 5. Tampilan Data Penghuni

Form pemesanan ini berfungsi untuk melakukan pemesanan lapangan futsal di kirana futsal dimana terlebih dahulu harus mengisi data data pemesanan.

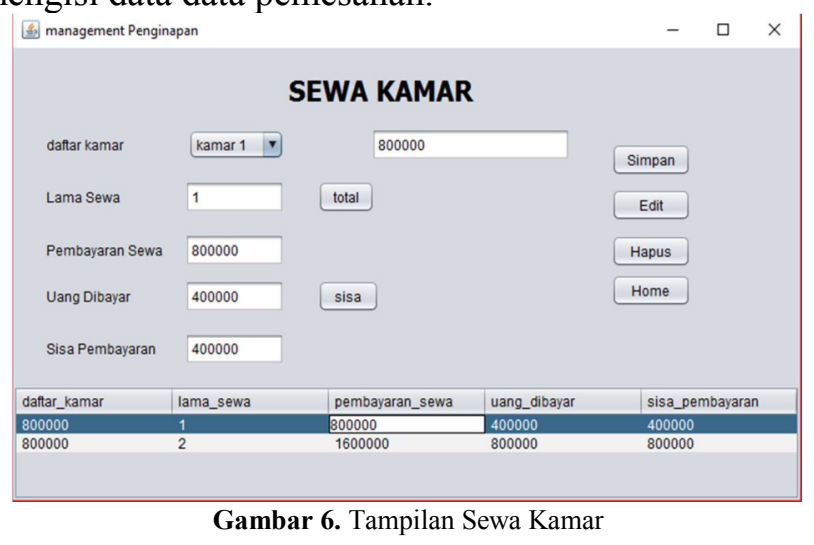

Form sewa kamar pengurus menginput pembayaran calon penghuni dan no kamar calon penghuni. 


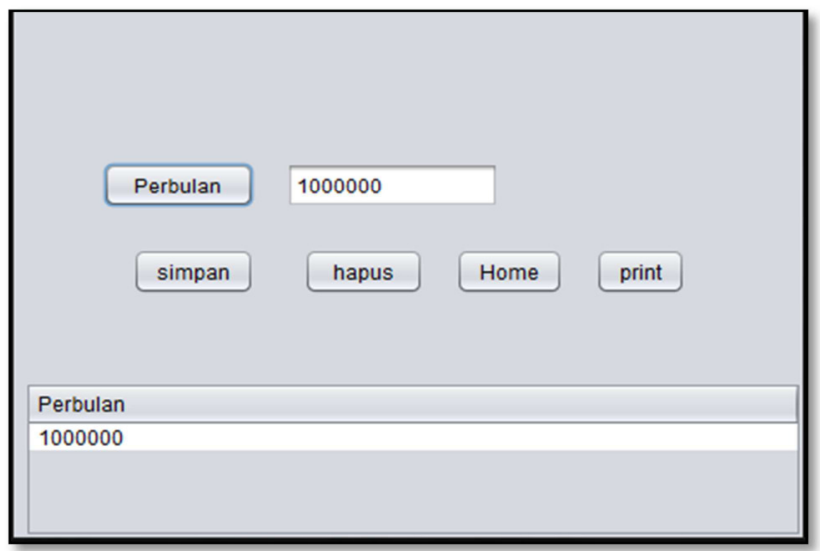

Gambar 7. Tampilan Pendapatan

Pada form ini pengurus menginput semua pendapatan dalam sebulan.

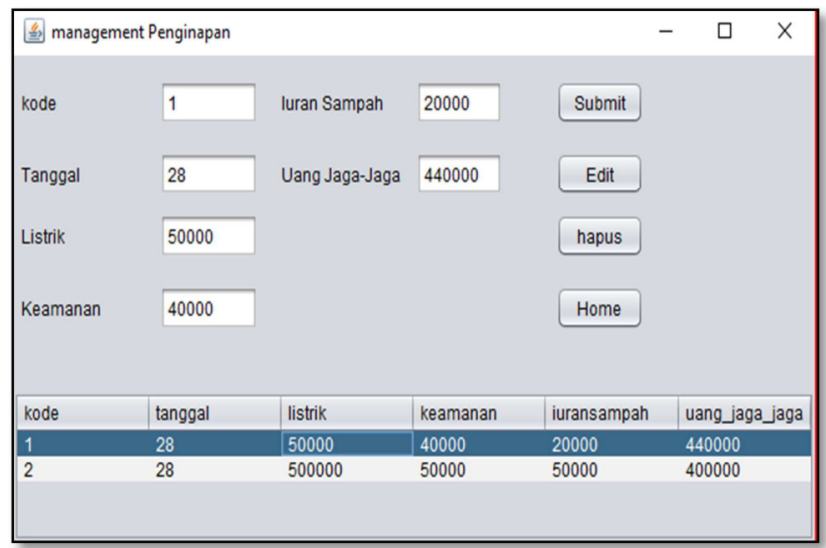

Gambar 8. Tampilan Pengeluaran

Form ini pengurus menginput pengeluaran penginpan dalam sebulan.

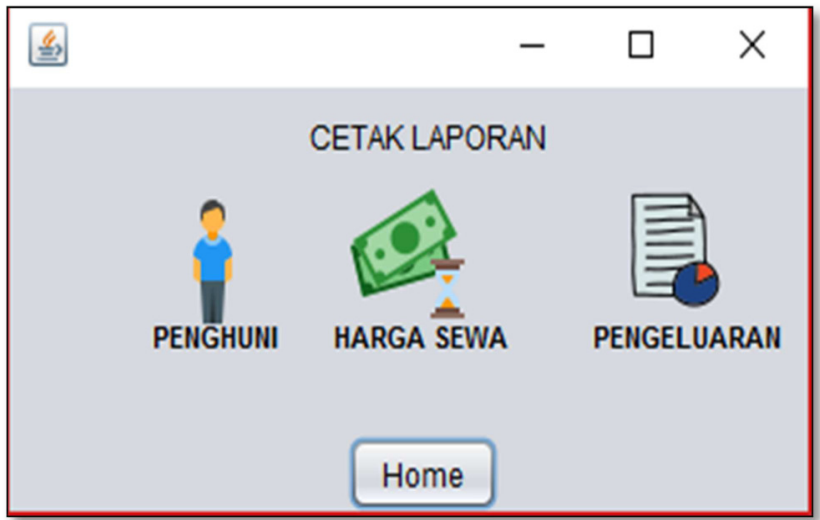

Gambar 9. Tampilan Report

Form ini pengurus bisa menampilkan report atau laporan dari setiap form yang ingin di tampilkan reportnya. 


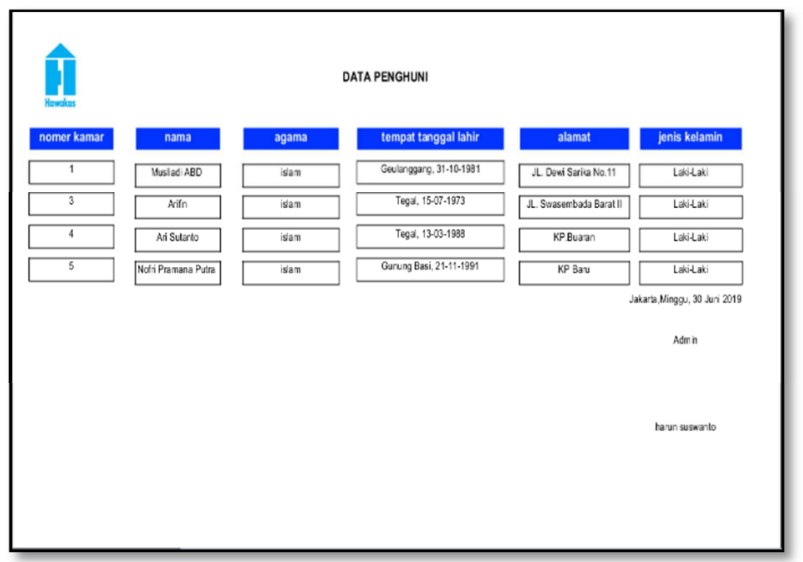

Gambar 10. Tampilan Laporan Data Penghuni

Form ini menampilkan rekap laporan ini dapat kita lakukan setelah menekan tombol print pada form report.

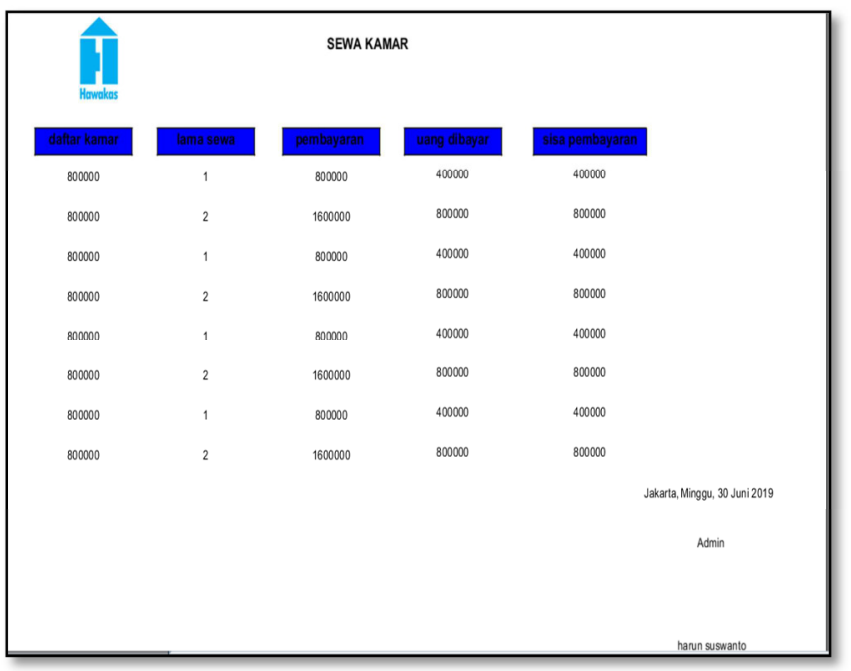

Gambar 11. Tampilan Laporan Sewa Kamar

Rekap laporan ini dapat kita lakukan setelah menekan tombol print pada from report.

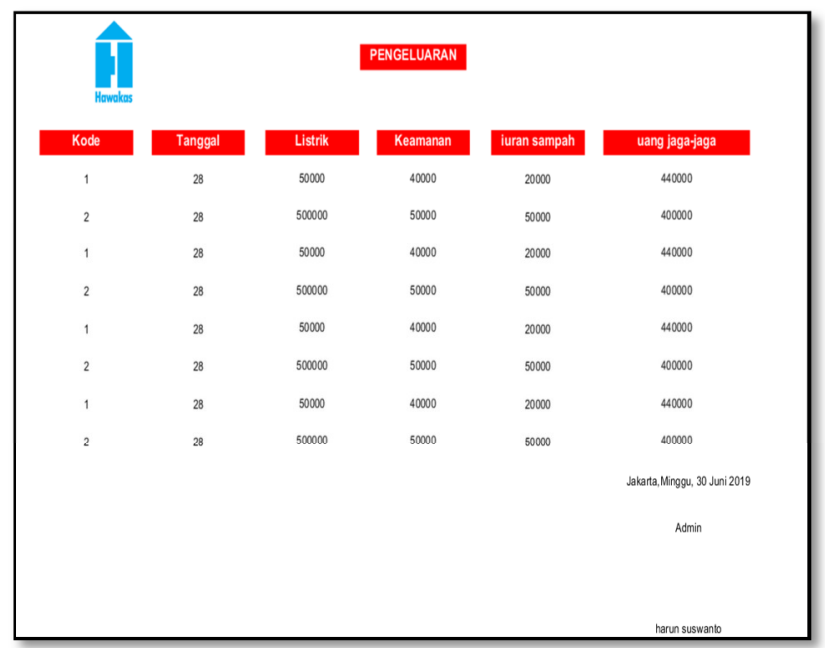

Gambar 12. Tampilan Laporan Pengeluaran

Rekap laporan ini dapat kita lakukan setelah menekan tombol print pada form report. 


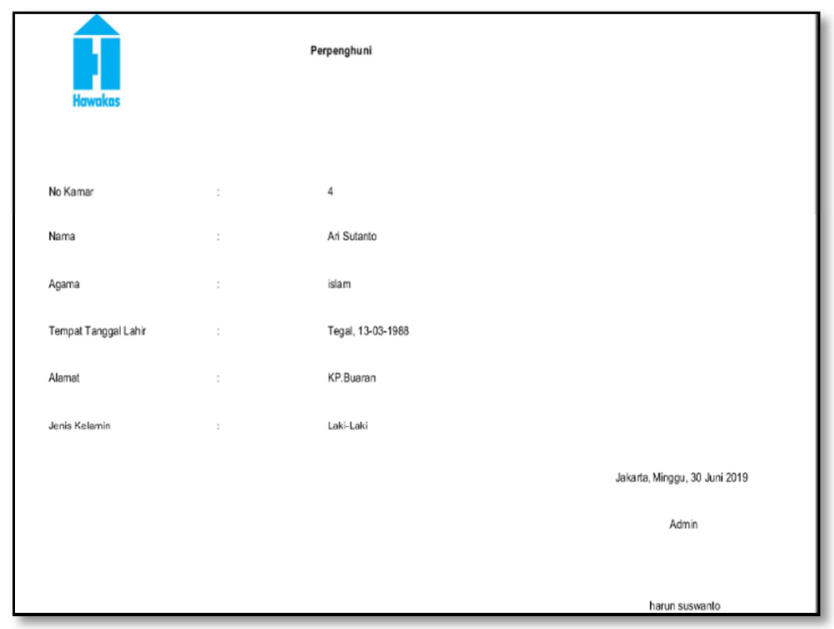

Gambar 13. Tampilan Laporan Perpenghuni

Rekap laporan ini dapat kita lakukan setelah menekan tombol print pada form penghuni.

\section{SIMPULAN}

Berdasarkan hasil analisis dan perancangan yang peneliti lakukan, maka dapat ditarik kesimpulan sebagai berikut:

a. Untuk merancang sebuah aplikasi yang dapat mempermudah dan mengamankan proses pengolahan data penghuni, pengeluaran, pemasukan, data sewa kamar penginapan hawakas yang berbasis desktop yang dapat menampilkan, menambahkan, serta memanipulasi data penghuni, data sewa kamar, dan data pengeluaran dan pemasukan.

b. Perancangan aplikasi penginapan hawakas cililitan jakarta timur dirancang dengan berbasis desktop menggunakan netbeans dengan bahasa pemograman Java dan MysSQL sebagai Database Management service.

c. Dengan menggunakan aplikasi ini, operasional dalam penyimpanan, pencatatan, dan pelaporan data penginapan akan lebih efisien.

Dengan adanya aplikasi program ini diharapkan dapat mempermudah dalam pengolahan ataupun pengadaan sistem data yang ada di Penginapan Hawakas secara komputerisasi.

\section{DAFTAR PUSTAKA}

Kustian, N., Bus, P. T., Aplikasi, S., \& Bus, T. (2019). PENGGUNAAN MODEL WATERFALL DALAM PEMBUATAN. 4(1), 94-104.

Maimunah; Hariyansyah; Jihadi, G. (2017). Rancang Bangun Sistem Aplikasi Penyewaan Lapangan Futsal Berbasis Web. Seminar Nasional Teknologi Informasi Dan Multimedia 2017, 7-12.

Maria Agustin. (2012). Analisis Dan Perancangan Sistem Informasi Reservasi Hotel. Jurnal Prosesor, 3, 10-13.

Mayasari, M. S. (2015). Perancangan Aplikasi Sistem Informasi Penyewaan Kaset (Cd) Pada Rental Kaset Akin Tanjung Pendam. Simetris: Jurnal Teknik Mesin, Elektro Dan Ilmu Komputer, 6(1), 47. https://doi.org/10.24176/simet.v6i1.236

Rosadi, D., \& Feby, O. A. (2016). Aplikasi Sistem Informasi Pencarian Tempat Kos Di Kota Bandung Berbasis Android. Jurnal Computech \& Bisnis, 10(1), 50-58. Retrieved from http://jurnal.stmikmi.ac.id/index.php/jcb/article/view/145/169 